\title{
A decadal cirrus clouds climatology from ground-based and spaceborne lidars above the south of France $\left(43.9^{\circ} \mathrm{N}-5.7^{\circ} \mathrm{E}\right)$
}

\author{
C. Hoareau $^{1}$, P. Keckhut ${ }^{2}$, V. Noel ${ }^{1}$, H. Chepfer ${ }^{1}$, and J.-L. Baray ${ }^{3}$ \\ ${ }^{1}$ LMD, UMR8539, INSU-CNRS, UPMC, Ecole Polytechnique, 91128 Palaiseau Cedex, France \\ ${ }^{2}$ LATMOS, UMR8190, INSU-CNRS, UVSQ, UPMC, 11 Boulevard d'Alembert, 78820 Guyancourt, France \\ ${ }^{3}$ LACy, UMR8105, 15 avenue René Cassin-BP 7151-97715 St-Denis Cedex 09, La Réunion, France
}

Correspondence to: C. Hoareau (christophe.hoareau@lmd.polytechnique.fr)

Received: 15 February 2013 - Published in Atmos. Chem. Phys. Discuss.: 11 March 2013

Revised: 28 May 2013 - Accepted: 17 June 2013 - Published: 23 July 2013

\begin{abstract}
This study provides an analysis of cirrus cloud properties at midlatitude in the southern part of France from ground-based and spaceborne lidars. A climatology of cirrus cloud properties and their evolution over more than $12 \mathrm{yr}$ is presented and compared to other mid-latitude climatological studies. Cirrus clouds occur $\sim 37 \%$ of the total observation time and remain quasi-constant across seasons with a variation within $\sim 5 \%$ around the mean occurrence. Similar results are obtained from CALIOP and the ground-based lidar, with a mean difference in occurrence of $\sim 5 \%$ between both instruments. From the ground-based lidar data, a slight decrease in occurrence of $\sim 3 \%$ per decade is observed but found statistically insignificant. Based on a clustering analysis of cirrus cloud parameters, three distinct classes have been identified and investigations concerning their origin are discussed. Properties of these different classes are analysed, showing that thin cirrus in the upper troposphere represent $\sim 50 \%$ of cloud cover detected in summer and fall, decreasing by $15-20 \%$ for other seasons.
\end{abstract}

\section{Introduction}

High-altitude clouds, like cirrus, have been recognised as important regulators of the radiative balance of the earthatmosphere system (Twomey, 1991), and cover at least 30\% of the Earth's surface (Liou, 1986; Rossow and Schiffer, 1999; Wylie and Menzel, 1999; Stubenrauch et al., 2006) based on passive measurements. Consequently, a good understanding of their physical properties is essential to determine the relative strengths of the solar albedo and infrared greenhouse effects at the top and within the atmosphere, as well as at the surface (Sassen and Campbell, 2001). Although the contribution of each effect depends strongly on cirrus optical properties (Zerefos et al., 2003), the altitude and the vertical extension of these clouds have an obvious impact on the radiative balance. Thin cirrus clouds usually cause a positive radiative forcing at the top of the atmosphere, while thick cirrus clouds may produce cooling ( $\mathrm{Fu}$ and Liou, 1993; Fahey and Schumann, 1999). Therefore, it is essential to identify and document these different parameters at different geographical locations to improve the parameterisation in numerical models and decrease uncertainties in climate prediction. Lidars designed to monitor cirrus clouds have been deployed at several observatories around the globe for more than a decade, producing regional climatologies from midlatitude (Goldfarb et al., 2001; Giannakaki et al., 2007) and tropical observatories (Comstock et al., 2002; Cadet et al., 2003; Thorsen et al., 2011). Lidar instruments can detect cirrus clouds with optical depths as low as $10^{-3}$ at visible wavelengths, whereas many passive satellite sensors require visible optical depths of $\sim 0.1$ for cirrus to be detected and, consequently, may underestimate the actual cirrus occurrence frequency. Lidar measurements provide accurate information on the vertical distribution of cirrus and, therefore, are now used to develop highly resolved cirrus database. The objective of this study is to construct a cirrus climatology over the period 19962007 using a ground-based Rayleigh-Mie-Raman lidar, use this unique dataset to investigate the lidar capabilities to describe their decadal evolutions and compare these results to those obtained from the spaceborne lidar CALIOP which 
provides global vertical profiling information of clouds since June 2006. Some studies have investigated cloud classification based on their macrophysical properties (Desbois et al., 1982; Keckhut et al., 2006). This kind of investigations should be useful to identify the different formation processes and their parameterisation in general circulation models. Also to further investigate the lidar dataset, a statistical multivariate analysis based on morphologic cloud information derived on a lidar sub-set has been performed.

Section 2 describes the design of the ground-based and spaceborne lidar instruments. Section 3 concerns the retrieval of cirrus clouds parameters. Climatology and data processing to identify the different cirrus cloud classes are presented in Sect. 4. Finally investigations about the cirrus clouds longterm evolution and discussion about their origin are respectively presented in Sect. 5 and Sect. 6.

\section{Instrumentation and data description}

\subsection{OHP Ground-based lidar}

The Rayleigh-Mie-Raman lidar at the Observatory of Haute Provence (OHP) makes measurements during nighttime throughout the year except in presence of low cloud and is situated at $43.9^{\circ} \mathrm{N}, 5.7^{\circ} \mathrm{E}$ and at $679 \mathrm{~m}$ altitude. A typical measurement period is of around $6 \mathrm{~h}$; however it depends on factors such as cloud cover evolution and availability of the operator. Usually lidar acquisitions are made 3-4 times per week. A brief overview of the instrument is given here; details can be found elsewhere (Keckhut et al., 1993; Hauchecorne et al., 1992; Sherlock et al., 1999). This lidar uses a doubled Nd-YAG laser which emits a light pulse of $\sim 10 \mathrm{~ns}$ at $532 \mathrm{~nm}$. The repetition rate is of $50 \mathrm{~Hz}$ with average pulse energy of $300 \mathrm{~mJ}$. Nitrogen Raman channel is an upgrade of the receiving optics of the Rayleigh temperature lidar that is a part of the Network for the Detection of Atmospheric Composition Change (NDACC). The cirrus channel used a $20 \mathrm{~cm}$ telescope and an optical fibre of $1 \mathrm{~mm}$ diameter. The field-of-view is equal to $1 \mathrm{mrad}$. Because the measurements were also dedicated to stratospheric aerosol analyses, an electronic shutter system has been added to reduce the induced noise due to initial burst. Due to this electronic shutter, clouds are only detected above $6 \mathrm{~km}$. For Raman channels, the backscattered signals are collected by a telescope of $80 \mathrm{~cm}$. The backscattered signals are collected by optical fibres mounted on the focal plane of these telescopes and transferred to the optical ensemble. Counts from 8000 shots $(160 \mathrm{~s})$ are pre-accumulated in $75 \mathrm{~m}(0.5 \mu \mathrm{s})$ bin intervals and stored to constitute the raw data. Temperatures used throughout the paper in relation with OHP lidar data were obtained from radiosondes (Vaïsala RS-80 - now modem), which are launched daily from Nîmes $(\sim 100 \mathrm{~km}$ from OHP) by the French meteorological centre (Météo-France) at mid- night, during lidar operations. The temperature difference between both locations should stay below a few Kelvins.

\subsection{CALIOP spaceborne lidar}

The CALIOP lidar, set on the Cloud Aerosol and Infrared Pathfinder Satellite Observations (CALIPSO) satellite, is designed to provide global vertical profiling information of clouds and aerosols. It was launched in April 2006 into a sunsynchronous orbit as part of the A-Train satellite constellation. A brief description is given here; details of the CALIOP instrument can be found in Hunt et al. (2009). CALIOP is a 2-wavelength $(532 \mathrm{~nm}$ and $1064 \mathrm{~nm})$ polarization sensitive lidar. Its laser generates optical pulses of $\sim 20$ ns with energy of $110 \mathrm{~mJ}$ at each of the two wavelengths and a repetition rate of $20.16 \mathrm{~Hz}$. Backscatter signals are collected by a $1 \mathrm{~m}$ diameter telescope. The fundamental sampling resolution of the lidar is $30 \mathrm{~m}$ vertical and $335 \mathrm{~m}$ horizontal. The high quality of processed CALIPSO data products has been demonstrated through validation campaigns (Winker et al., 2007; Vaughan et al., 2008) and comparisons studies with ground-based instruments (Plana-Fattori et al., 2009; Dupont et al., 2010; Thorsen et al., 2011). In this study, we compare the regional quality of climatological cirrus cloud properties from CALIOP to those observed from the ground-based lidar at the OHP. To conduct this comparison study, we have analysed CALIOP measurements of cirrus clouds over the OHP site from June 2006 to December 2012. We considered CALIOP observations obtained in the vicinity of the observatory in a domain small enough to remain consistent with the ground-based statistics, and large enough to obtain enough samples to derive statistics. In an area $100 \mathrm{~km}$ wide, CALIOP will only sample twice per 16 day repeat cycle, providing 45 sampling opportunities per year. Extending the domain to a $2^{\circ} \times 6^{\circ}$ latitude-longitude box yields 300 (day + night) overpasses with about 45 samples each, resulting in about 14000 samples (as in Dupont et al., 2010). Temperature used through the paper in relation with CALIOP data come from the GEOS-5 general circulation model reanalyses, which are included in CALIOP data files.

\section{Cirrus cloud properties retrieval}

\subsection{OHP Ground-based lidar}

Between 1996 and 2007, the lidar recorded about $7000 \mathrm{~h}$ of measurements. To build the cirrus clouds database, as in Hoareau et al. (2009) we adjusted the integration time according to discontinuities in the optical thickness time series. An example is provided in Fig. 1. We followed an iterative method designed to find the multiple change points in value series (Lanzante et al., 1996). The first step of the sampling methodology is to identify the presence of clouds based in the optical thickness time series retrieved in the altitude range 6-15 km (which correspond to the extreme values of base 

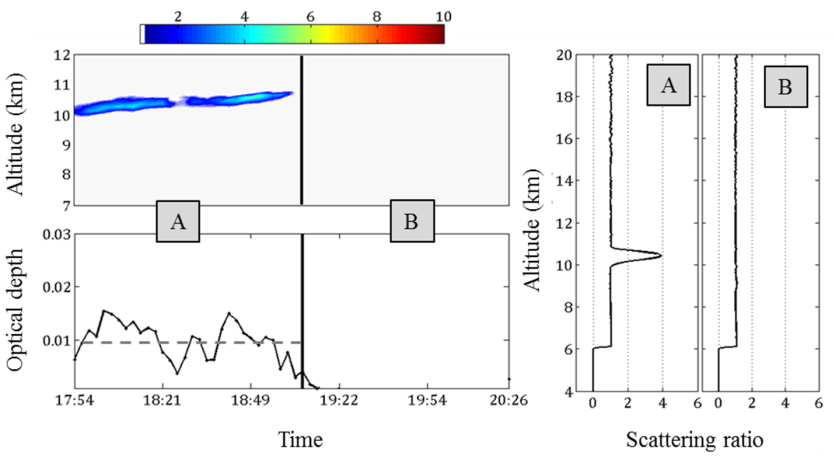

Fig. 1. Data sampling method. On the left, the top panel represents the evolution of a cirrus cloud over time. The bottom panel corresponds to the optical thickness for the same period. For both panels the vertical black line shows when a significant change point in the optical thickness time series is detected, leading to the situation A (with cirrus cloud) and B (without cirrus cloud). The corresponding scattering ratio profiles for both situations, $\mathrm{A}$ and $\mathrm{B}$, are illustrated on the right.

and top altitude of cirrus clouds) using the pre-accumulated lidar signals (over $2 \mathrm{~min} 40 \mathrm{~s}$ ). We then temporally integrate the pre-accumulated lidar signals between discontinuities (points in the optical thickness time series where a statistical change is observed), over periods that represent quasistationary conditions. Such periods are assumed to be representative of unchanged cloud properties and long enough to provide a better statistical estimator of the cirrus cloud physical properties. Clouds parameters used in this study are determined using these time-integrated profiles. Clouds are then identified as cirrus according to two criteria. First, the cloud layer must be as cold as $-25^{\circ} \mathrm{C}$ (Goldfarb et al., 2001). Second, the Scattering Ratio (SR), defined as the ratio of the total (molecular and particle) backscatter coefficient divided by the molecular backscatter coefficient, must be above a defined threshold. Because molecular backscattering can be estimated by a dry air density profile, it can be retrieved from the Nitrogen signal, so SR can be derived from the ratio of the power in the Rayleigh-Mie and Raman vibrational Nitrogen channel (Ferrare et al., 2001). Here we define the SR threshold as its average plus three times its standard deviation in the $17-19 \mathrm{~km}$ altitude range. Although aerosols might be present in this altitude range and affect the signal, higher altitudes cannot be used due to the noise increase in Nitrogen Raman signal. The boundaries of cirrus clouds are defined as the altitudes where the scattering ratio falls below the SR threshold. A profile is multi-layer if the SR stays below the threshold for least $225 \mathrm{~m}$ (three successive height intervals) between two successive layers.

From visible lidar backscatter, only the vertical cloud structure (top and base altitude, geometrical thickness) can be derived directly with a good accuracy and without any additional assumptions. Even when using polarization and several wavelengths, retrieving optical and microphysical parameters from lidar requires making many assumptions about the particle type, shape and size within the cloud. In addition, this retrieval requires very accurate signals, that for a given lidar (Cadet et al., 2005) are not possible when clouds are too thin (too weak differential signals) or too deep (too large lidar signal attenuation above cloud). In our case, even if we should theoretically be able to retrieve the extinction and thus, the optical thickness directly from the Raman channel, the Nitrogen backscatter signal is often too noisy for an accurate retrieval. Retrieving the optical thickness from the visible channel requires knowing the extinction-to-backscatter ratio, also known as the Lidar Ratio (LR), which depends on particle shape and size within the cloud. The estimation of the LR includes significant uncertainty in case of thin or thick clouds. Recent studies of cloud optical properties have shown the LR frequency distribution is centred at $25 \pm 15 \mathrm{sr}$ for ice clouds (Yorks et al., 2011). This value is consistent with other lidar measurements made using this technique (Giannakaki et al., 2007; Immler and Schrems, 2002). In order to have the same confidence in all cases, including thin or thick clouds, and following the literature, we decided to use a constant LR of $25 \mathrm{sr}$.

For optically thick cirrus, the LR can be affected by multiple scattering. This effect depends on factors including laser penetration depth, cloud range and height, the field-of-view of the receiver, particle size distribution and shape (Eloranta, 1998; Hogan and Illingworth, 2003). Sassen and Comstock (2001) assumed a multiple scattering factor $\eta$ of 0.9 for subvisible cirrus clouds, of 0.8 for relatively thick clouds and 0.6 to 0.7 for optically thick clouds. For this study, we chose $\eta=0.75$, which implies an uncertainty of about $20 \%$ on the retrieved optical thickness.

We derived the optical thickness ( $\left.\tau_{\text {cirrus }}\right)$ from SR profiles by the following expression (e.g. Goldfarb et al., 2001):

$\tau_{\text {cirrus }}=\eta \cdot \mathrm{LR} \cdot \sigma_{\text {rayleigh }} \int_{z_{\min }}^{z_{\max }} n_{\text {air }}(z) \cdot(\mathrm{SR}(z)-1) \mathrm{d} z$

where $\beta_{\text {rayleigh }}=\sigma_{\text {rayleigh }} \cdot n_{\text {air }}(z)$ and the air density number $n_{\text {air }}(z)$ are calculated by the Mass Spectrometer Incoherent Scatter-Extended-1990 (MSISE-90) atmospheric model, and $\sigma_{\text {rayleigh }}(532 \mathrm{~nm})=5.7 \times 10-32 \mathrm{~m}^{2} \mathrm{sr}^{-1}$.

\subsection{Macrophysical and optical properties from CALIOP}

In this study, we use the CALIPSO Level 2 v3.01 and 3.02 $5 \mathrm{~km}$ cloud layer product to characterise cirrus clouds macrophysical and optical properties. The nominal vertical resolution of CALIPSO data is $30 \mathrm{~m}$ from the surface to $8.2 \mathrm{~km}$ and $60 \mathrm{~m}$ from $8.2 \mathrm{~km}$ to $20.2 \mathrm{~km}$. Cloud layers are identified in CALIPSO backscatter using the selective iterative boundary locator (SIBYL) (Vaughan et al., 2009) which consists of an algorithm that scans profiles to detect aerosol and cloud layers, and an algorithm to average profiles and remove detected 

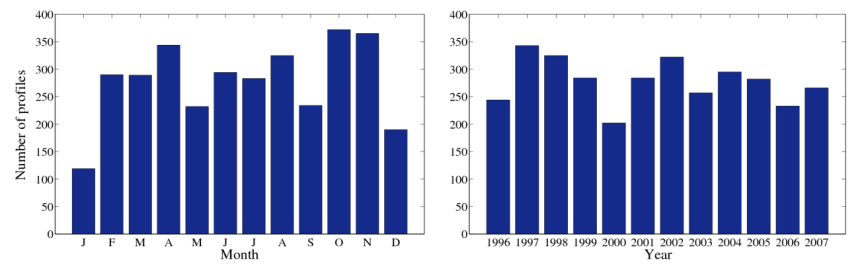

Fig. 2. Total number of profiles obtained over OHP site during the period 1996-2007 from the ground-based lidar for each month (on the left) and year (on the right).

layers from the profiles before further averaging. Cloud layers are identified by examining the enhancement of the return signal relative to the molecular background using a threshold algorithm (Winker et al., 2009). In the multiscale approach, the layer finding algorithm performs multiple passes through the data increasing the amount of horizontal averaging at each pass. After cloud layers are identified at a particular horizontal resolution they are removed before moving on to further averaging. In the $5 \mathrm{~km} \mathrm{~L} 2$ cloud product three horizontal averaging distances are considered: $5,20,80 \mathrm{~km}$. In this study, we consider CALIPSO cloud properties retrieved at all three distances.

To retrieve the cirrus clouds optical thickness, CALIOP cloud products use three methods: (1) the transmittance method which requires a clear air signal below the cloud layer, (2) the lidar equation using a LR of $25 \mathrm{sr}$ and (3) the lidar equation with an adjustment of the LR to avoid unphysical optical thickness. The large majority $(\sim 90 \%)$ of CALIPSO cloud optical thickness uses a fixed LR and a multiple scattering factor of $\eta=0.6$ for all retrieval types (Thorsen et al., 2011).

\section{Cirrus clouds climatology}

As noted in Sect. 3.2 the ground-based lidar at OHP performed systematic measurements over $12 \mathrm{yr}$ (1996-2007). Due to the irregularity of OHP measurements after 2007 due to frequent instrumental failures, their sampling might not be statistically representative of cirrus cloud properties and we will not use them. Based on the methodology used to construct the cirrus clouds database (see Sect. 3.1), over the 1996-2007 period around 3300 profiles (with cirrus in $\sim 1850$ cirrus profiles) have been obtained, with a total of $\sim 280$ profiles per month over this period (Fig. 2). The total measurements time is of $\sim 7000 \mathrm{~h}$ including $\sim 2650 \mathrm{~h}$ where cirrus clouds have been observed. Fewer measurements were obtained in 1996 and 2007. CALIOP has measured a mean of $\sim 270$ profiles (with cirrus in $\sim 90$ cirrus profiles) per month during nighttime from June 2006 through December 2012 (Fig. 3). That means around 3250 profiles per year, except in 2006. Although the data sampling is different for both instruments, it is interesting to compare the results obtained

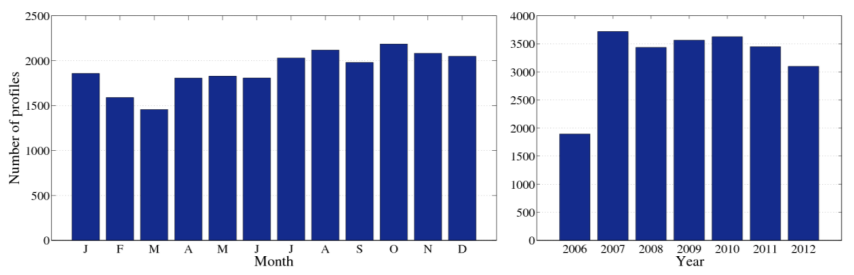

Fig. 3. Total number of profiles obtained over OHP site during nighttime from CALIOP for each month (on the left) and year (on the right) over the period 2006-2012.

for both databases. Contrary to the adaptive sampling used for OHP data, CALIOP uses three finite integration periods that depend on the detection or not of a cloud $(5 \mathrm{~km}, 20 \mathrm{~km}$ or $80 \mathrm{~km}$, see Sect. 3.2).

\subsection{Cirrus clouds classification}

From the cirrus clouds parameters retrieved from both instruments, a distribution analysis has been performed. Figure 4 show the probability distribution functions (PDFs) of six cloud properties. These properties were derived from lidar measurements, except the mid-cloud temperature (Fig. 4, bottom right) that comes from radiosondes (Sect. 2.1). As these PDFs are not Gaussian, it could be a possible indication of the presence of different classes. For example, the PDF of the cloud top height (Fig. 4, top left) suggests two modes, centred near $12 \mathrm{~km}$ and $9 \mathrm{~km}$. The same can be said for the cloud thickness (Fig. 4, bottom left), with two modes centred at $\sim 1 \mathrm{~km}$ and $\sim 3 \mathrm{~km}$. However, visual analysis can be deceptive, and cannot lead to definite conclusions. To discriminate possible cirrus classes more efficiently, we used cluster analysis, a convenient method to separate observations in homogeneous groups. In our case, observations (defined by the cirrus cloud parameters: cloud top and mean height, geometrical and optical thickness, mid-cloud temperature) are aggregated into a small number of clusters based on the dissimilarities between them using a Hierarchical Agglomerative Clustering (HAC) algorithm (Jain and Dubes, 1988), and based on Euclidean distance. HAC is performed following the Ward criterion (Ward, 1963), which ensures that one will find, at each step, a local minimum of the intra-class inertia (sum of the inertia of the different observations). The aim of HAC is that each observation belonging to a cluster should be as close as possible to another observation of this cluster, and as far as possible from an observation belonging to any other cluster. The final number of clusters is selected choosing the most significant discriminative partition with respect to the dendrogram of the HAC. This dendrogram allows identifying the statistical optimum number of classes, i.e. the level in the dendrogram where there is a significant change of the aggregation index, based on the intra-classes variance using the Ward distance metric. Here, the HAC, performed on the OHP lidar data, suggests the existence of three 

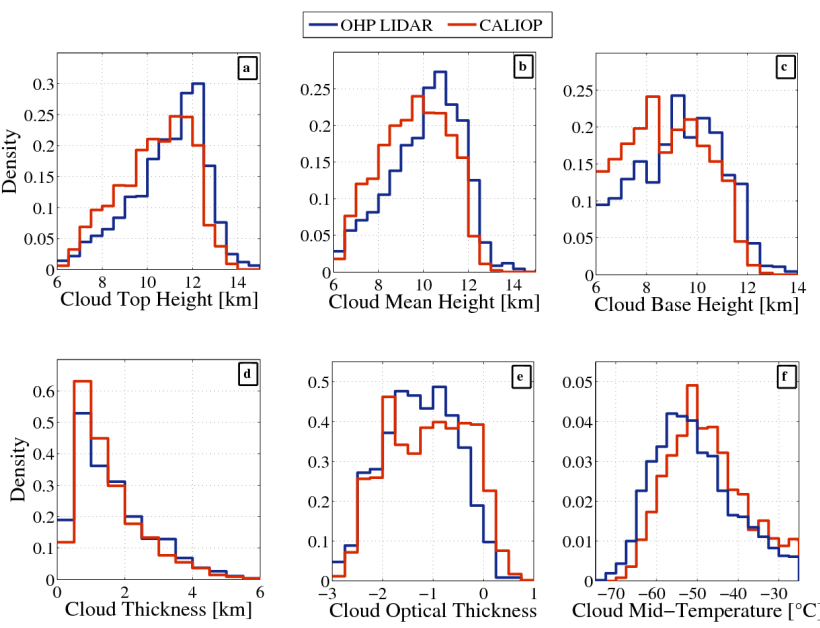

Fig. 4. Probability density functions of macrophysical cirrus clouds parameters derived from the OHP lidar (blue) and CALIOP (red). (a) to (f) correspond respectively to the distribution of the cloud top, mean and base height, the cloud geometrical and optical thickness, and the mid-cloud temperature.

distinct classes (Fig. 5, left). To ensure the multivariate analysis is robust, we performed a Discriminant Factorial Analysis (DFA). This supervised discrimination technique, applied on already-classified data, identifies the optimal set of orthogonal projection axes which best separate the classes. These axes are the discriminant factors, selected to minimise the probability of mis-classification. As three classes have been previously identified, the analysis is done along two discriminant axes, F1 and F2 (Fig. 5, right). The DFA corroborates $\sim 91.5 \%$ of HAC classifications and re-affects $\sim 8.5 \%$ from one class to another. The discriminant axes F1 and F2 represent respectively $59.3 \%$ and $40.7 \%$ of the discrimination. We find a correlation of $94.5 \%$ between the $\mathrm{F} 1$ axis and the top of cirrus clouds, and $81.6 \%$ between the F2 axis and the geometrical cloud thickness. Therefore, these two parameters seem to be the most important to discriminate the different classes. Performing the multivariate analysis on CALIOP data over the OHP site also indicates three classes identified from the HAC analysis (not shown). For CALIOP data, the DFA corroborates $\sim 91.8 \%$ of HAC classifications. Results also show a strong correlation between F1 axis and the cloud top height $(\sim 95.4 \%)$, and F2 axis and the cloud thickness $(\sim 82.4 \%)$. The mean and standard deviation for all parameters of each cirrus class are listed in Table 1. We compare in Table 1 these results to a previous classification conducted on one year of cirrus cloud observations from the OHP lidar (Keckhut et al., 2006). Although the statistical methods used are different, the present analysis from ground-based and spaceborne lidar data shows similar results regarding the number of identified classes and the behaviour of cirrus parameters in each class.

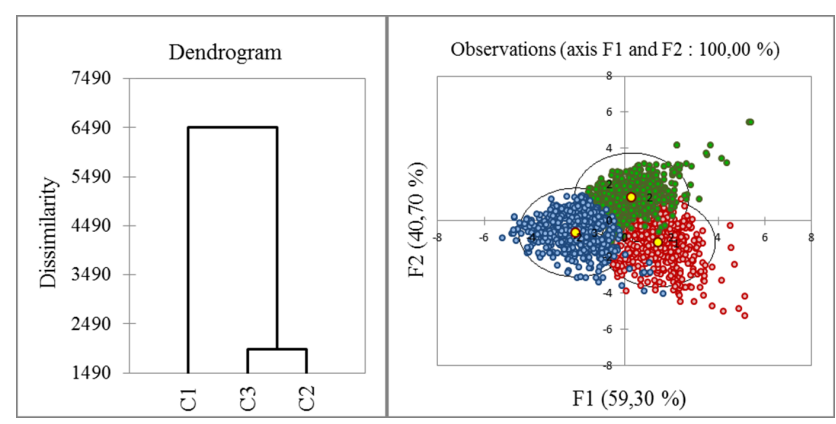

Fig. 5. Classification of the different observations from the OHP lidar. Left panel: dendrogram of the dissimilarity index between the observations performed by the hierarchical agglomerative clustering method. Right panel: observations along two discriminant axes, F1 and F2, which represent a linear combination of the different cirrus clouds parameters used in the HAC. Class 1, 2 and 3 are respectively represented by blue, green and red dots.

\subsection{Cirrus clouds occurrence}

Over the OHP, cirrus clouds occur $\sim 37 \%$ of the observation time. Subvisible cirrus (SVC, with optical thickness <0.03) are observed $\sim 38 \%$ of this time, or $\sim 14 \%$ of the total observation time. These results are different from those of Goldfarb et al. (2001), hereafter G01, who reported occurrences of $\sim 54 \%$ for cirrus clouds and $\sim 25 \%$ for SVC over the OHP for 1997-1999. These significant differences can be explained by definitions of cloud occurrences. G01 calculates cirrus occurrence from the number of nightly measurements with cirrus divided by the total number of nightly measurements. Here, cirrus occurrence is defined as the ratio of cirrus detection time on the total measurement time. A re-analysis of the G01 dataset for the 1997-1999 period using our methodology gives a cirrus occurrence frequency of $\sim 37 \%$ over the OHP. Overall, cirrus occurrences from the OHP lidar and CALIOP remain quasi-constant (Fig. 6), with variations within $5 \%$ around the mean occurrence observed across seasons for both instruments. The maximum occurrence is in spring: $\sim 42 \%$ (OHP lidar) and $\sim 38 \%$ (CALIOP). The minimum is in summer: $\sim 33 \%$ (OHP lidar) and $\sim 29 \%$ (CALIOP). The mean difference between instruments is $\sim 5 \%$.

Regarding the occurrence of cirrus clouds classes, for classes 1 and 2, cirrus clouds are more frequently observed during winter and spring (Fig. 7). For class 1, during winter and spring, the mean occurrences represent $\sim 32 \%$ (OHP lidar) and $\sim 35 \%$ (CALIOP) of cloud cover detected, and decrease to $\sim 24 \%$ and $\sim 23 \%$ in mean during summer and fall. For class 2, mean occurrences are similar: from $\sim 33 \%$ (OHP lidar) and $\sim 38 \%$ (CALIOP) of the cloud cover detected during winter and spring, to $\sim 26 \%$ and $\sim 31 \%$ during summer and fall. Regarding class 3, variations are opposite across seasons and more important. Maximum occurrence 
Table 1. Characteristics of the different classes identified over the Observatory of Haute Provence (OHP) site. Class 1 to 3 represent respectively thin cirrus in the middle troposphere (Thin MT), thick cirrus in the upper troposphere (Thick UT) and thin cirrus in the upper troposphere (Thin UT). The references A, B and C correspond respectively to the update analyses (1996-2007), the analyses performed by Keckhut et al. (2006) over the year 2000 and in using the CALIPSO data up to now (2006-2012).

\begin{tabular}{|c|c|c|c|c|}
\hline Characteristic & Reference & Class 1 Thin MT & Class 2 Thick UT & Class 3 Thin UT \\
\hline \multirow[t]{3}{*}{ Occurrence $(\%)$} & A & 28 & 30 & 42 \\
\hline & $\mathrm{B}$ & 36 & 27 & 35 \\
\hline & $\mathrm{C}$ & 30 & 33 & 37 \\
\hline \multirow[t]{3}{*}{ Mean altitude $(\mathrm{km})$} & $\mathrm{A}$ & $8.1 \pm 1$ & $10.4 \pm 1$ & $11.2 \pm 1.1$ \\
\hline & $\mathrm{B}$ & $8.6 \pm 0.9$ & $9.8 \pm 0.7$ & $11.5 \pm 0.9$ \\
\hline & $\mathrm{C}$ & $7.9 \pm 0.7$ & $9.8 \pm 0.6$ & $10.8 \pm 0.6$ \\
\hline \multirow[t]{3}{*}{ Geometrical thickness (km) } & $\mathrm{A}$ & $1.3 \pm 0.8$ & $2.9 \pm 1$ & $1 \pm 0.4$ \\
\hline & $\mathrm{B}$ & $0.9 \pm 0.6$ & $3.2 \pm 0.9$ & $0.9 \pm 0.6$ \\
\hline & $\mathrm{C}$ & $1 \pm 0.4$ & $2.6 \pm 1$ & $1 \pm 0.5$ \\
\hline \multirow[t]{3}{*}{ Optical Depth } & A & $0.1 \pm 0.2$ & $0.5 \pm 0.4$ & $0.07 \pm 0.06$ \\
\hline & $\mathrm{B}$ & $0.2 \pm 0.2$ & $0.8 \pm 0.4$ & $0.1 \pm 0.1$ \\
\hline & $\mathrm{C}$ & $0.2 \pm 0.5$ & $0.6 \pm 0.6$ & $0.1 \pm 0.3$ \\
\hline \multirow[t]{3}{*}{ Top altitude (km) } & A & $8.8 \pm 1$ & $11.9 \pm 0.9$ & $11.7 \pm 1$ \\
\hline & $\mathrm{B}$ & - & - & - \\
\hline & $\mathrm{C}$ & $8.4 \pm 0.8$ & $11.1 \pm 0.9$ & $11.3 \pm 0.7$ \\
\hline \multirow[t]{3}{*}{ Mean temperature $\left({ }^{\circ} \mathrm{C}\right)$} & A & $-38 \pm 9$ & $-52 \pm 6$ & $-56 \pm 7$ \\
\hline & $\mathrm{B}$ & $-41 \pm 6$ & $-50 \pm 6$ & $-58 \pm 6$ \\
\hline & $\mathrm{C}$ & $-37 \pm 9$ & $-49 \pm 6$ & $-55 \pm 6$ \\
\hline
\end{tabular}

is in summer and fall. During these seasons, cirrus clouds represent $\sim 49 \%$ (OHP lidar) and $\sim 46 \%$ (CALIOP) of the cloud cover detected. During winter and spring, the relative part of these clouds decrease by 15-20\% with mean occurrence observed of $\sim 34 \%$ and $\sim 26 \%$ for the OHP lidar and CALIOP, respectively.

We find no clear relation between monthly averages of cirrus occurrence and mid-cloud temperature when all cirrus clouds are considered. Correlation coefficients between both are $\sim-0.2$ from OHP lidar data and $\sim-0.5$ from CALIOP data (Fig. 8). However, we find higher correlations when different classes are considered: -0.72 (OHP) and -0.93 (CALIOP) for class 1 . Occurrence, for this class, increases by $\sim 5-10 \%$ when the mid-cloud temperature decreases by $\sim 10^{\circ} \mathrm{C}$. The same trend is observed for class 2 , even if the correlation between both parameters is weaker $(r=-0.52$ and -0.57 , respectively for OHP and CALIOP data). Finally a good correlation was found between the occurrence of class 3 cirrus clouds and the mid-cloud temperature ( $r=0.83$ and 0.72 , respectively for OHP and CALIOP data). For those clouds, contrary to classes 1 and 2, midcloud temperature and occurrence are positively correlated; occurrence increases by a rather weak, $\sim 5 \%$, was found when mid-cloud temperature rises by $\sim 10^{\circ} \mathrm{C}$.

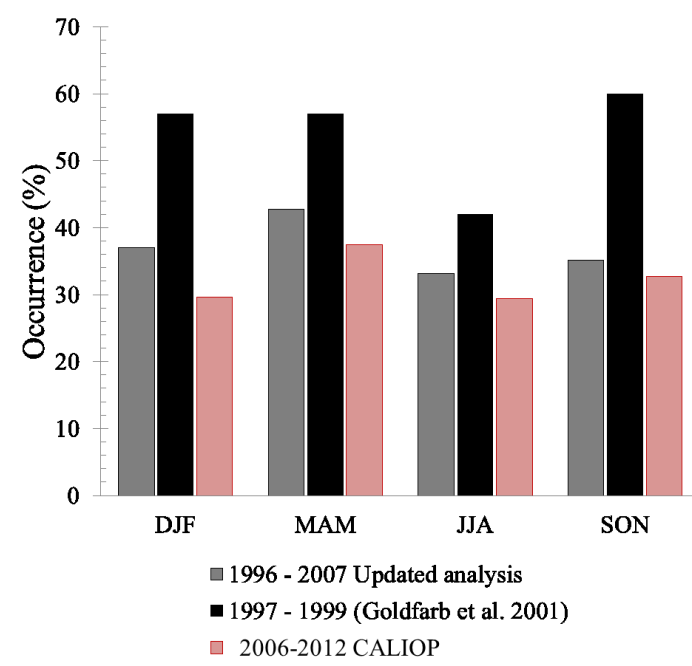

Fig. 6. Seasonal cirrus clouds occurrence over the OHP site from our analysis of OHP lidar data (gray), from Goldfarb et al. (2001) (black) and from CALIOP data (red).

\subsection{Macrophysical properties}

The mean Cloud Thickness (CT) retrieved from the OHP lidar (all cirrus clouds) is $1.64 \pm 1.11 \mathrm{~km}$. This is smaller than values from previous mid-latitude studies of cirrus clouds 


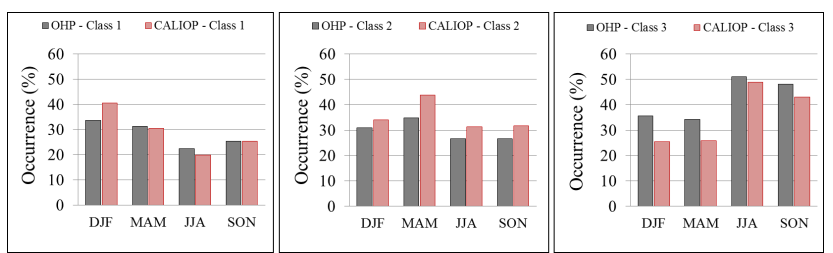

Fig. 7. Seasonal cirrus clouds occurrence over the OHP site according to the different cirrus clouds classes. Panels $(\mathbf{A}, \mathbf{B}, \mathbf{C})$ represent the class 1 (thin cirrus in middle troposphere), 2 (thick cirrus in upper troposphere) and 3 (thin cirrus in upper troposphere), respectively. For each histogram, the gray bars represent the results obtained from the OHP lidar data and the red bars those derived from the CALIOP data.

over Western North America $\left(40^{\circ} \mathrm{N}\right)(2.79 \pm 1.38 \mathrm{~km})$ by Sassen and Comstock (2001) (hereafter SC01) and over South Europe $\left(40.6^{\circ} \mathrm{N}\right)(2.7 \pm 0.9)$ by Giannakaki et al. (2007) (hereafter G07). It is however in good agreement with Min et al. (2011) (hereafter M11) who found a mean CT of $1.60 \pm 1.15 \mathrm{~km}$ over North China $\left(35-45^{\circ} \mathrm{N}\right)$, and with G01 who found a mean CT of $1.4 \pm 1.3 \mathrm{~km}$. Our results from the OHP lidar are also in good agreement with the mean CT of $1.56 \pm 1 \mathrm{~km}$ we derived from CALIOP data over the OHP (cf. Table 2). Cloud Base Height (CBH) we derived from the OHP lidar agree with most of these studies and those retrieved from CALIOP data $(9.28 \pm 1.77 \mathrm{~km}$, $9 \pm 1.1 \mathrm{~km}, 9.16 \pm 1.83 \mathrm{~km}$ and $8.85 \pm 1.56 \mathrm{~km}$ respectively for this study, G07, M11 and CALIOP data), except with SC01 who found a mean $\mathrm{CBH}$ of $8.17 \pm 1.95 \mathrm{~km}$. We found a mean Cloud Top Height (CTH) of $10.94 \pm 1.68 \mathrm{~km}$, in good agreement with M11, SC01 and CALIOP data $(10.77 \pm 0.9 \mathrm{~km}, 10.97 \pm 1.72 \mathrm{~km}$ and $10.4 \pm 1.62 \mathrm{~km}$, respectively) but smaller than the one reported by G07 $(11.7 \pm 0.9 \mathrm{~km})$. Globally, cirrus clouds physical parameters over the OHP are similar to results obtained by M11, and most parameters agree well with other studies. To further analyse cirrus cloud properties derived from CALIOP over the OHP and those derived from the OHP lidar, we also compared both datasets (1996-2007 and 2006-2012, respectively for OHP lidar and CALIOP) during the coincident period (June 2006 to June 2007). During this period, the difference observed between both datasets decrease. CTH and CBH observed from the OHP lidar are higher than those observed from CALIOP by $\sim 0.1 \mathrm{~km}$ on average $(\sim 0.5 \mathrm{~km}$ for the extended period). For CT, difference between both datasets is similar for the extended and coincident period and keeps inferior to $0.1 \mathrm{~km}$.

As discussed previously (Sect. 4.1), three distinct classes of cirrus clouds have been retrieved from the OHP lidar and CALIOP observations: a first class of thin cirrus $(\sim 1 \mathrm{~km})$ in the middle troposphere (mid-height of $\sim 8 \mathrm{~km}$ ), a second one thicker $(\sim 3 \mathrm{~km})$ at $\sim 10 \mathrm{~km}$ and a last one with a thickness of $\sim 1 \mathrm{~km}$ at $\sim 11 \mathrm{~km}$. Considering the different classes re-

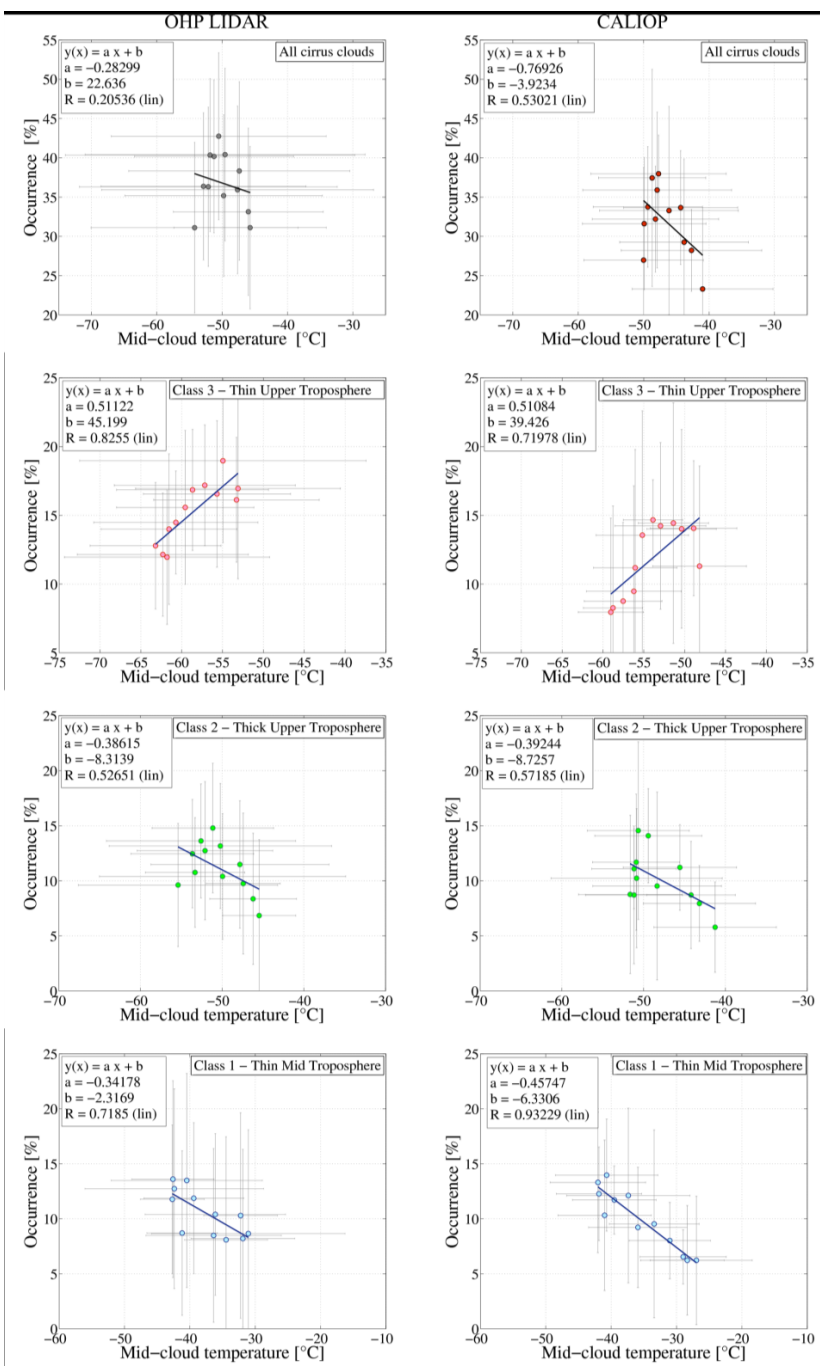

Fig. 8. Monthly cirrus clouds occurrence as a monthly mid-cloud temperature function. The line represents the best linear fitting of the cirrus clouds occurrence as a temperature function for the different classes. Slope, intercept and correlation coefficient are presented on the left-upper corner of panels. Standard deviations are shown in gray. Class 1, 2 and 3 are presented C1, C1 and C3 labels on the right-upper corner of panels.

trieved during the extended period, monthly means of physical parameters for each class have been examined (Fig. 9). The variability of $\mathrm{CT}$ for each class is relatively constant across months, with a mean monthly variation of $\sim 0.05 \mathrm{~km}$ around the mean CT for the class 1 , of $\sim 0.1 \mathrm{~km}$ for the class 3 and the largest, $\sim 0.3 \mathrm{~km}$, for the class 2 (the class with thickest clouds). These values have been retrieved from OHP lidar and CALIOP data (mean CT for each class is shown in Table 1). Similar results have been retrieved regarding the variability of Cloud Mean Height which keeps quite constant from one month to another. A mean monthly variation of $\sim 0.15 \mathrm{~km}$ around the total mean value has been observed 
Table 2. Cirrus clouds macrophysical properties comparison. CBH, CTH and CT represent respectively the Cloud Top Height, Cloud Base Height and Cloud Thickness. Extended Period (1996-2007 and 2006-2012, respectively for the ground-based lidar and CALIOP) is represented by EP and Coincident Period between the ground-based lidar and CALIOP over the OHP (June 2006 to June 2007) by CP. Previous mid-latitude studies are represented by SC01 (Sassen and Comstock, 2001), G07 (Giannakaki et al., 2007) and M11 (Min et al., 2011).

\begin{tabular}{|c|c|c|c|c|c|c|c|}
\hline & \multicolumn{4}{|c|}{ OHP (This study) } & \multirow[t]{3}{*}{ SC01 } & \multirow[t]{3}{*}{ G07 } & \multirow[t]{3}{*}{ M11 } \\
\hline & \multicolumn{2}{|c|}{ Ground-based lidar } & \multicolumn{2}{|c|}{ CALIOP } & & & \\
\hline & EP & $\mathrm{CP}$ & EP & $\mathrm{CP}$ & & & \\
\hline $\mathrm{CBH}[\mathrm{km}]$ & $9.28 \pm 1.77$ & $9.4 \pm 1.76$ & $8.85 \pm 1.95$ & $9.35 \pm 1.47$ & $8.17 \pm 1.95$ & $9 \pm 1.1$ & $9.16 \pm 1.83$ \\
\hline CTH $[\mathrm{km}]$ & $10.94 \pm 1.68$ & $11.03 \pm 1.84$ & $10.4 \pm 1.62$ & $10.91 \pm 1.48$ & $10.97 \pm 1.92$ & $11.7 \pm 0.9$ & $10.77 \pm 0.9$ \\
\hline $\mathrm{CT}[\mathrm{km}]$ & $1.64 \pm 1.1$ & $1.64 \pm 1.1$ & $1.56 \pm 1$ & $1.56 \pm 1$ & $2.79 \pm 1.38$ & $2.7 \pm 0.9$ & $1.6 \pm 1.15$ \\
\hline
\end{tabular}

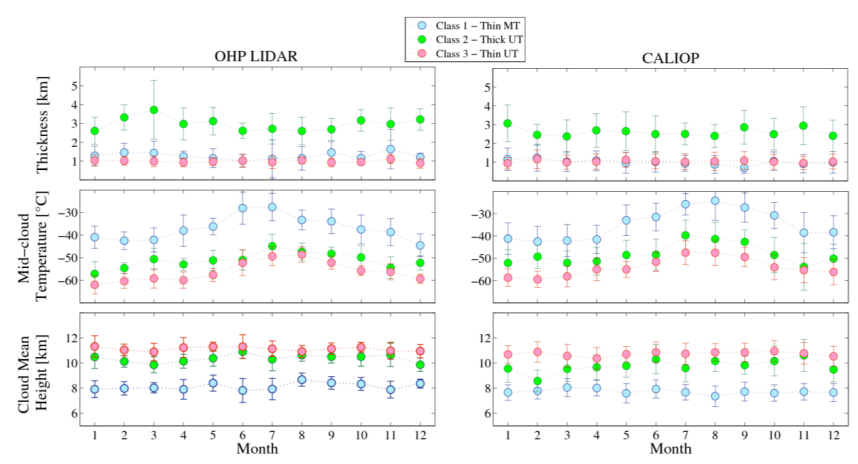

Fig. 9. Monthly mean of macrophysical parameters of the different cirrus clouds classes. The blue, green and red lines represent respectively the results for the class 1 (thin cirrus in middle troposphere), the class 2 (thick cirrus in upper troposphere) and the class 3 (thin cirrus in upper troposphere). Panels on the left correspond to the OHP lidar data and those on the right to CALIOP data. From the top to bottom are respectively presented the cirrus clouds thickness, mid-cloud temperature and the mean height of the clouds.

for the class 1 and 3 from both CALIOP and the OHP lidar, and of $\sim 0.3 \mathrm{~km}$ for the class 2 . Parameters for class 2 cirrus clouds agree well with results from G07. This could suggest that cirrus clouds occurring over Thessaloniki in South Europe are mainly from class 2 .

\subsection{Dependence of cirrus cloud properties on temperature}

The dependence of cirrus clouds optical depth and geometrical thickness on mid-cloud temperature is presented in Fig. 10. Considering all cirrus clouds, clouds are thickest $(\sim 2 \mathrm{~km})$ near $\sim-42.5^{\circ} \mathrm{C}$, and thinner at warmer and colder temperatures (Fig. 10, bottom). This is true for OHP lidar and CALIOP data over the OHP. These results are in agreement with SC01 and G07, but disagree with M11, who found that clouds were thicker at warmer temperatures. The largest optical depths are observed at $\sim 42.5^{\circ} \mathrm{C}$, and are smaller for warmer and colder temperatures. At colder temperatures (near $-65^{\circ} \mathrm{C}$ ), optical depths are small compared to warm
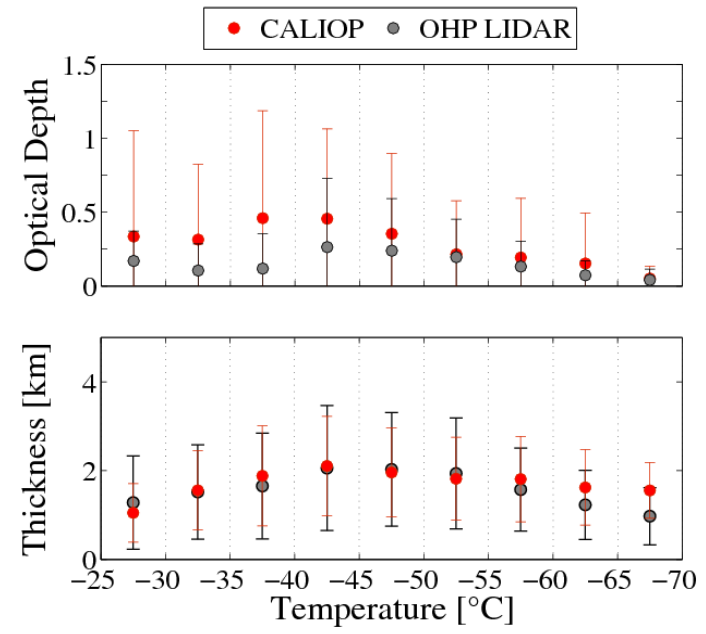

Fig. 10. Average optical depth (top) and geometrical thickness (bottom) in $5{ }^{\circ} \mathrm{C}$ intervals of mid-cloud temperature. Results presented in red correspond to CALIOP and those in gray to the OHP groundbased lidar.

temperatures (near $-30^{\circ} \mathrm{C}$ ) although cloud thickness for these temperatures is similar $(\sim 1 \mathrm{~km})$. These trends appear in CALIOP and OHP lidar data, however optical depths from CALIOP are generally larger than those from the OHP lidar. This difference is more important for cirrus clouds with midcloud temperature warmer than $-45^{\circ} \mathrm{C}$. For these temperatures, optical depths retrieved from CALIOP are $\sim 2.5$ times larger than those from the OHP lidar, against $\sim 1.5$ times at temperatures colder than $-45^{\circ} \mathrm{C}$. However, the differences we find between optical depths derived by CALIOP and the OHP lidar all fall within uncertainty intervals. When different classes are considered (Fig. 11), cloud thicknesses as well as optical depths belonging to class 1 and 3 seem quite constant with temperatures. Class 2 clouds show an increase in thickness and optical depth with warmer temperature up to $\sim 37.5^{\circ} \mathrm{C}$. At even warmer temperatures, optical depth and thickness decrease slightly according to CALIOP data. The OHP lidar did not observe enough cirrus from this class at 


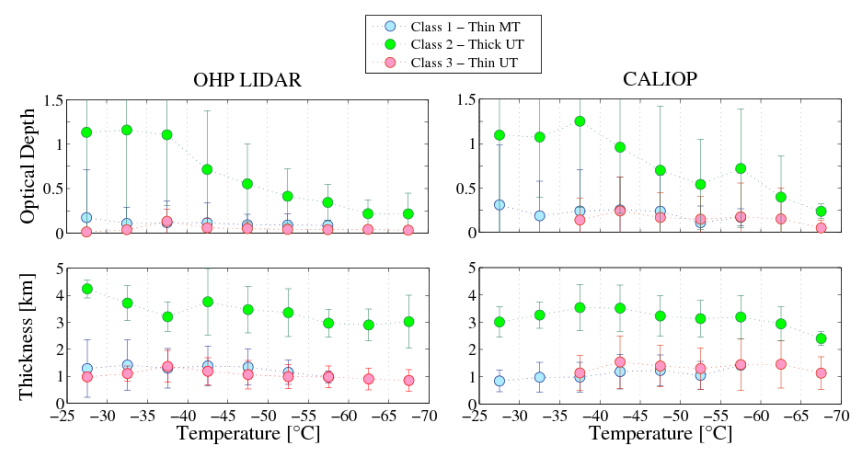

Fig. 11. Average optical depth (top) and geometrical thickness (bottom) in $5^{\circ} \mathrm{C}$ intervals of mid-cloud temperature for each cirrus clouds class. Panels on the left correspond to the analysis performed from OHP lidar data and panels on the right correspond to those performed from CALIOP.

temperatures warmer than $-37.5^{\circ} \mathrm{C}$ to support any conclusion.

\section{Cirrus clouds long-term evolution}

Because the OHP database spans more than $12 \mathrm{yr}$, it becomes possible to examine the evolution of cirrus occurrence frequency and macrophysical properties. We restricted most of our analysis to OHP lidar observations; although we include an investigation regarding the extension of OHP lidar data with CALIOP data in an attempt to estimate the decadal variation of cirrus clouds parameters.

\subsection{Occurrence}

In curve fitting, it makes sense to give the least amount of weight to points that are the least reliable. This is properly accomplished statistically by weighting each point by the inverse square of its standard error when calculating the best-fit slope. This is particularly important in our case, given the inhomogeneity in acquisition time over the period 1996-2007 (a few hours up to several tens of hours per month). Here, we relate the standard error of cirrus clouds occurrence to the acquisition time. Figure 12 shows the most frequent integration time is $\sim 30 \mathrm{~min}$, for nearly $25 \%$ of profiles obtained. If we considered that each observation of $30 \mathrm{~min}$ profile represents an independent observation, which is statistically the case considering the sampling method used (Sect. 1), each profile derived from the sampling methodology can be considered as an independent sample of a finite population. The size of the population, depending on the month, has a fixed upper bound of $n$ profiles of $30 \mathrm{~min}$. Therefore, it is possible to construct a confidence interval on the statistic computed from sample information, which is used to estimate the cirrus clouds occurrence of the entire population. The mean standard error associated to this occurrence is on average $\sim 10 \%$ over the whole period, $\sim 15 \%$ before 1999 and $\sim 9 \%$ after

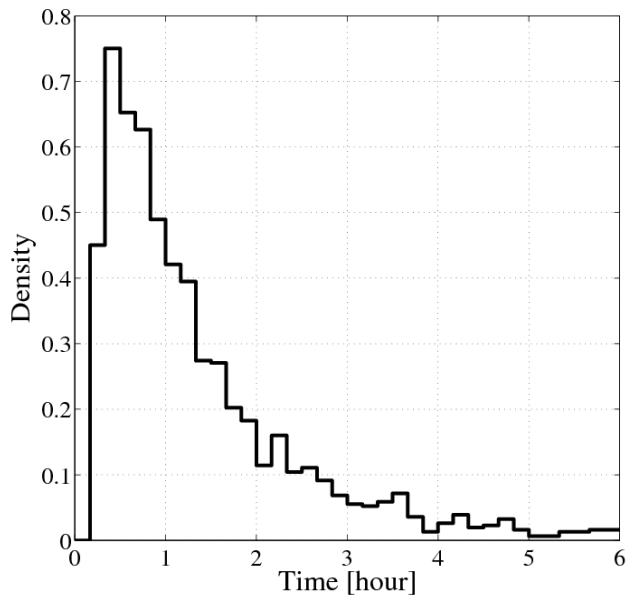

Fig. 12. Probability density function of the integration time for OHP lidar data. Integration time is determined from the data sampling method (See Sect. 3.1 for details).

(Fig. 13). For weighted least squares straight line fitting, the best fit values of the slope $a$ and the intercept $b$, when the error resides with $y_{i}$, are then given by:

$a=\frac{\sum_{i=1}^{n} w_{i} \sum_{i=1}^{n} w_{i} x_{i} y_{i}-\sum_{i=1}^{n} w_{i} x_{i} \sum_{i=1}^{n} w_{i} y_{i}}{\sum_{i=1}^{n} w_{i} \sum_{i=1}^{n} w_{i} x_{i}^{2}-\left(\sum_{i=1}^{n} w_{i} x_{i}\right)^{2}}$

and

$b=\frac{\sum_{i=1}^{n} w_{i} x_{i}^{2} \sum_{i=1}^{n} w_{i} y_{i}-\sum_{i=1}^{n} w_{i} x_{i} \sum_{i=1}^{n} w_{i} x_{i} y_{i}}{\sum_{i=1}^{n} w_{i} \sum_{i=1}^{n} w_{i} x_{i}^{2}-\left(\sum_{i=1}^{n} w_{i} x_{i}\right)^{2}}$

where the weight is defined by

$w_{i}=1 /\left(\sigma_{i}^{2}\right)$

and $\sigma_{i}$ is the standard error associated to the value $y_{i}$.

We find a slight, and statistically insignificant, decrease of $\sim 3 \%$ per decade in cirrus clouds occurrence. The corresponding standard deviation of the residuals and the prediction interval of the linear regression are shown in Fig. 14. By performing the same analysis on the different classes (Sect. 4.1), the occurrence of class 1 cirrus increases by $\sim 0.8 \%$ per decade. For the class 2 , the occurrence increases slightly more: $\sim 1.8 \%$ per decade. In contrast, for class 3 , the occurrence decreases by $\sim 3.2 \%$ per decade. For these analyses, the error estimate is more than one standard deviation and corresponds to a $90 \%$ confidence interval $(\alpha=0.1)$. For each class, the variations indicated have not been found statistically significant considering this confidence interval. By superimposing the cirrus occurrence time series from CALIOP and from the OHP lidar, a slight difference of about $1 \%$ is observed during the coincident period (Fig. 15). This difference increases by the end of 2007 to reach $5 \%$. Although this difference is probably due to the sampling and the algorithm in use for each instrument, the tilt of laser emission 


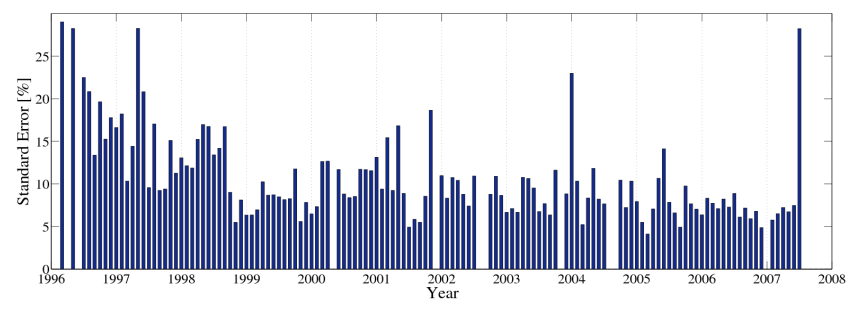

Fig. 13. Sampling standard error. The histogram represents the standard error of the cirrus clouds occurrence shown in Fig. 14. It is based on the duration of the lidar acquisition per month.

that occurred for CALIOP at the end of 2007 (see, for example, Noel and Chepfer, 2010) could play a role in the slight decrease in cirrus clouds occurrence retrieved by CALIOP from this date. However, more investigations are needed to verify this.

\subsection{Macrophysical properties}

Here we investigate the decadal variation of macrophysical cirrus cloud properties. Considering all cirrus clouds and the same approach as in Sect. 5.1 regarding the curve fitting method, we find a slight and statistically significant $(\alpha=0.1)$ increase in cloud thickness of $\sim 0.15 \mathrm{~km}$ per decade. Regarding the cloud mean height $(\mathrm{CMH})$, we found no significant change. By taking into account the different classes (Sect. 4.1), we find statistically insignificant longterm changes in $\mathrm{CMH}:+0.06 \mathrm{~km},-0.13 \mathrm{~km}$ and $-0.14 \mathrm{~km}$ per decade for class 1,2 and 3, respectively. We find that $\mathrm{CT}$ increases for all classes. This variation is not statistically significant for class $1(\sim 0.07 \mathrm{~km}$ per decade $)$, but is significant for class $2(+0.35 \mathrm{~km}$ per decade $)$ and $3(+0.2 \mathrm{~km}$ per decade).

\section{Summary and discussion}

This study provides an analysis of cirrus cloud properties at midlatitude in the southern part of France from groundbased and spaceborne lidars. Based on the ground-based lidar database which spans more than $12 \mathrm{yr}$, a climatology of cirrus cloud properties and their evolution over time have been presented and compared to CALIOP over the OHP site and other mid-latitude climatological studies. Our results show that cirrus occur $\sim 37 \%$ of the total observation time and subvisible cirrus represent $\sim 38 \%$ of these observations, or $\sim 14 \%$ of the total observation time. We have also shown overall cirrus occurrence remain quasi-constant across seasons. CALIOP and the ground-based lidar lead to similar results, with a mean difference in occurrence of $\sim 5 \%$ between both instruments. Cirrus clouds were observed at a mean height of $\sim 10.1 \mathrm{~km}$ with a mean thickness of $\sim 1.6 \mathrm{~km}$. Clouds are thickest (geometrically and optically) at tempera- tures of $\sim-42.5^{\circ} \mathrm{C}$ (mid-cloud temperature), and are thinner at warmer and colder temperatures. Comparisons with other mid-latitude studies reveal quite good agreement although some discrepancies, depending to the parameter observed, have been indicated and may be related to geographical differences in cirrus types. Our findings based on a clustering analysis show and re-affirm the presence of 3 distinct cirrus cloud classes over the OHP with similar results regarding the behaviour of cirrus parameters in each class both for CALIOP and the ground-based lidar: thin cirrus in the middle troposphere (class 1), thick cirrus in upper troposphere (class 2) and thin cirrus in upper troposphere (class 3). Although it is difficult to infer from our results the origin of cirrus from these classes, complementary studies and case studies can provide some hints. Thin cirrus clouds $(\sim 1 \mathrm{~km})$ in the upper troposphere (similar to class 3) have already been observed over OHP, investigated (Keckhut et al., 2005) and found to be associated with air masses coming from subtropical regions. Numerical simulations using an isentropic transport model were able to reproduce such type of clouds (Montoux et al., 2010), confirming they originate in the isentropic transport of moist air from subtropical regions to midlatitudes and can be classified as synoptic cirrus. They are formed into filamentary wet tongues, and appear a relatively short time on lidar observations. Their thin vertical extension is in good agreement with the clustering analysis. Cirrus from the second class (thick upper troposphere) probably come from more "standard" meteorological phenomena, of larger scales associated with relatively fast ascension of warm air mass due to frontogenese processes. Finally, cirrus from the third class (thin middle troposphere) could originate from contrails formed by aircrafts. Lamquin et al. (2012) report that such clouds could be expected over Europe around $250 \mathrm{hPa}$ mainly because this area is frequently saturated with respect to ice. The thickness of these observed clouds and the altitude of saturated air let us think that this 3rd class could be associated to old contrails turned into cirrus clouds.

Analysing the properties of these different classes indicated that $\sim 50 \%$ of cirrus clouds observed in summer and fall are from class 3, decreasing by $15-20 \%$ in winter and spring. For class 1 and 2, opposite variations have been observed. Cirrus of these classes are more frequent during winter and spring, and each class represents $\sim 30-35 \%$ of cirrus clouds observations during this period, decreasing by $5-10 \%$ during summer and fall. Moreover, the occurrence of clouds from these two classes increases by $\sim 5-10 \%$ when midcloud temperature drops by $\sim 10^{\circ} \mathrm{C}$, with anti-correlation coefficients of $\sim 0.8$ (class 1 ) and $\sim 0.5$ (class 2). For clouds from the class 3 , a correlation of $\sim 0.8$ between occurrence and mid-cloud temperature has been found, with occurrence increasing by $\sim 5 \%$ when mid-cloud temperature rises by $\sim 10^{\circ} \mathrm{C}$. This unexpected result for class 3 seems to indicate that temperature is not the main pertinent parameter. The case studies analysed previously indicate that wet air coming from the Tropics through filament may be the origin of these 

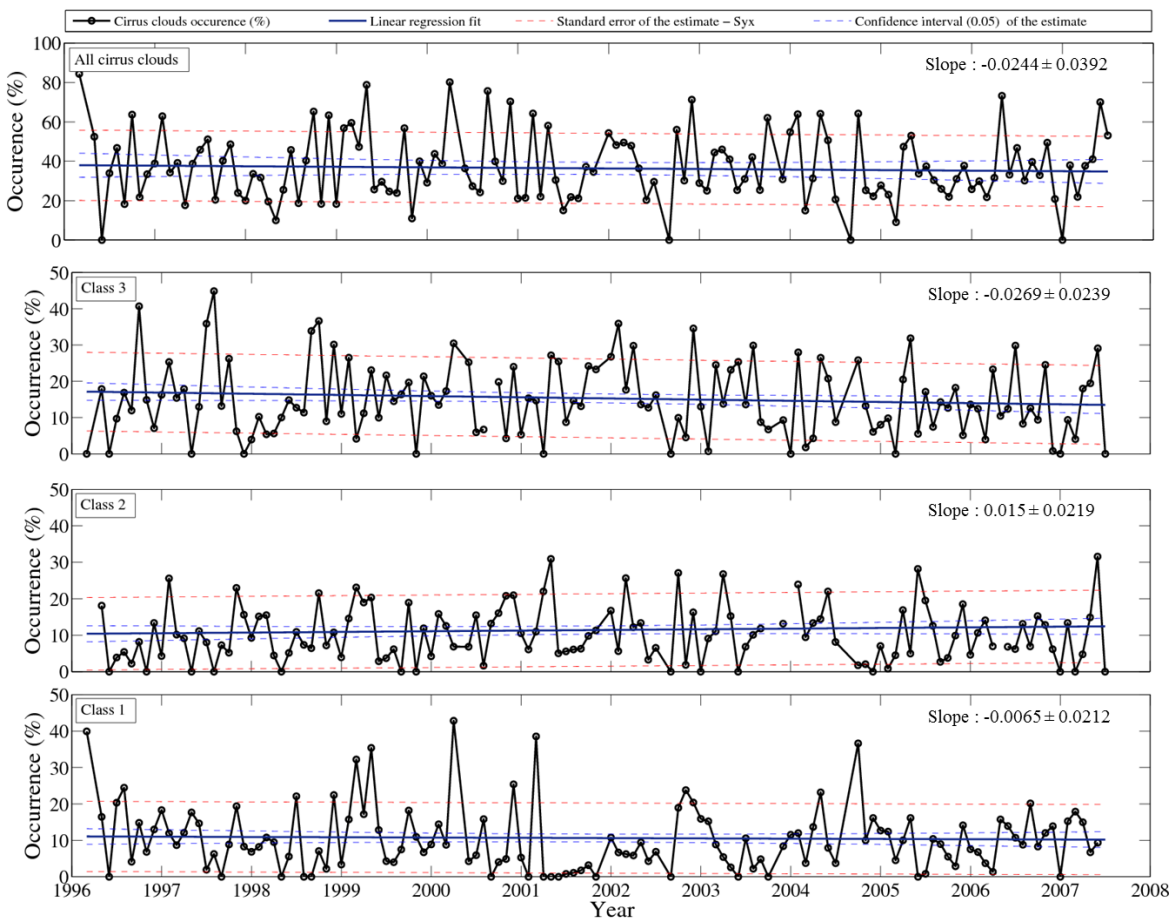

Fig. 14. Evolution of cirrus clouds occurrence from the OHP lidar. The black line with dots represents the cirrus clouds occurrence considering all cirrus clouds (top row) and each class (indicated at the top left corner of panel). The blue line represents the linear trend calculated over the entire time series (see Sect. 5.1 for details). Dashed blue lines represent the confidence interval (0.9) of the estimate and the dashed red lines the standard error of the estimate.

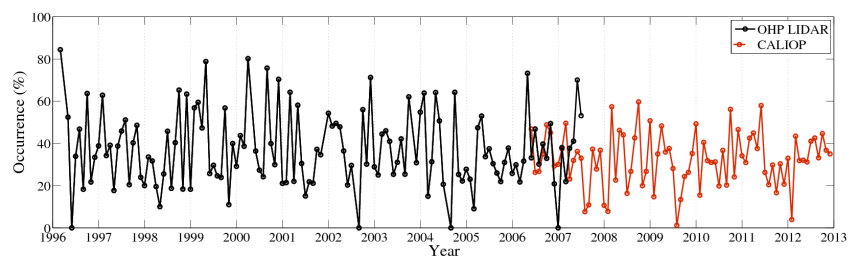

Fig. 15. Evolution of cirrus clouds occurrence from the OHP lidar (black) and CALIOP (red), considering all cirrus clouds.

cirrus clouds. In this case, one could expect their occurrence be driven primarily by circulation patterns. These patterns are probably also correlated with temperature, which would explain the positive correlation.

Finally, we could not find a statistically significant trend in long-term cirrus cloud occurrence. Conclusions were similar when considering different classes. We find no significant long-term trend in cloud height, either taking into account all cirrus clouds or each class separately. Finally, we find a statistically significant increase in cloud thickness for cirrus clouds from class 2 and 3 , of $\sim 0.35 \mathrm{~km}$ and $\sim 0.2 \mathrm{~km}$, respectively.

As more investigations are required to confirm attribution assumptions for cirrus cloud classes, we plan to investigate the origin of these classes by analysing the relationship between synoptic conditions and clouds observations for the different classes. It will improve the understanding of cloud formation processes and their parameterisation in models. As a good agreement has been found for the identification of cirrus clouds classes over the OHP between CALIOP and the ground-based lidar, we also plan to apply the clustering analysis to all CALIOP detections.

Acknowledgements. These systematic lidar observations are performed with the pluri-annual support of CNES and INSU. Authors thank CNES (Centre National d'Etudes Spatiales) for the direct support of this research in the frame of the CALIOP mission through the funding support of Christophe Hoareau. These cloud monitoring activities are coordinated in France within the SOERE ROSEA project supported by the Alliance Allenvi. CALIPSO data were produced by the NASA Langley Research Center Atmospheric Data Center, and obtained through the ICARE thematic pole.

Edited by: M. Krämer 
The publication of this article is financed by CNRS-INSU.

\section{References}

Cadet, B., Goldfarb, L., Faduilhe, D., Baldy, S., Giraud, V., Keckhut, P., and Rechou, A.: A sub-tropical cirrus clouds climatology from Reunion Island $\left(21^{\circ} \mathrm{S}, 55^{\circ} \mathrm{E}\right)$ lidar dataset, Geophys. Res. Lett., 30, 30.1-30.4, 2003.

Cadet, B., Giraud, V., Haeffelin, M., Rechou, A., and Baldy, S.: Improved retrievals of the optical properties of cirrus clouds by a combination of lidar methods, Appl. Opt., 44, 1726-1734, 2005.

Comstock, J. M., Ackerman, T. P., and Mace, G. G.: Ground-based lidar and radar remote sensing of tropical cirrus clouds at Nauru Island: Cloud Statistics and radiative impacts, J. Geophys. Res., 107, 4714, doi:10.1029/2002JD002203, 2002.

Desbois, M., Seze, G., and Szejwach, G.: Automatic classification of clouds on METEOSAT imagery: Application to high-level clouds, J. Appl. Meteor., 21, 401-412, 1982.

Dupont, J.-C., Haeffelin, M., Morille, Y., Noël, V., Keckhut, P., Winker, D. M., Comstock, J. M., Chervet, P., and Roblin, A.: Macrophysical and optical properties of midlatitude cirrus clouds from four ground-based lidars and collocated CALIOP observations, J. Geophys. Res., 115, D00H24, doi:10.1029/2009JD011943, 2010.

Eloranta, E.: Practical model for the calculation of multiply scattered lidar returns, Appl. Opt., 37, 2464-2474, 1998.

Fahey, D. W. and Schumann, U.: Aviation-Produced Aerosols and Cloudiness, Chapters 3 in Aviation and Global Atmosphere, A Special Report of IPCC (Intergovernmental Panel on Climate Change), edited by: Penner, J. E., Griggs, D. H., Dokken, D. J., and McFarland, M., Cambridge University Press, Cambridge, UK, 65-120, 1999.

Ferrare, R. A., Turner, D. D., Heilman Brasseur, L., Feltz, W. F., Dubovick, O., and Tooman, T. P.: Raman lidar measurements of the aerosol extinction-to backscatter ratio over the Southern Great Plains, J. Geophys. Res., 106, 20333-20347, 2001.

$\mathrm{Fu}$, Q. and Liou, K. N.: Parametrization of the radiative properties of cirrus clouds, J. Atmos. Sci., 50, 2008-2025, 1993.

Giannakaki, E., Balis, D. S., Amiridis, V., and Kazadzis, S.: Optical and geometrical characteristics of cirrus clouds over a Southern European lidar station, Atmos. Chem. Phys., 7, 5519-5530, doi:10.5194/acp-7-5519-2007, 2007.

Goldfarb, L., Keckhut, P., Chanin, M.-L., and Hauchecorne, A.: Cirrus climatological results from lidar measurements at OHP (44 N, $6^{\circ}$ E), Geophys. Res. Lett., 28, 1687-1690, 2001.

Hauchecorne, A., Chanin, M.-L., Keckhut, P., and Nedeljkovic, D.: Lidar monitoring of the temperature in the middle and lower atmosphere, App. Phys. B, 55, 29-34, 1992.

Hoareau, C., Keckhut, P., Baray, J.-L., Sarkissian, A., and Durry, G.: Methodology for water monitoring in the upper troposphere with Raman lidar at Observatory of Haute-Provence, J. Atmos. Ocean. Technol., 26, 2149-2160, 2009.

Hogan, R. J. and Illingworth, A. J.: Parameterising ice cloud inhomogeneity and the overlap of inhomogeneities using cloud radar data, J. Atmos. Sci., 60, 756-767, 2003.

Hunt, W. H., Winker, D. M., Vaughan, M. A., Powell, K. A., Lucker, P. L., and Weimer, C.: CALIPSO Lidar Description and Performance Assessment, J. Atmos. Ocean. Technol., 26, 1214-1228, 2009.

Immler, F. and Schrems, O.: LIDAR measurements of cirrus clouds in the northern and southern midlatitudes during INCA $\left(55^{\circ} \mathrm{N}\right.$, $53^{\circ} \mathrm{S}$ ): A comparative study, Geophys. Res. Lett., 29, 1809, doi:10.1029/2002GL015076, 2002.

Jain, A. K. and Dubes, R. C.: Algorithms for Clustering Data, Prentice-Hall, Englewood Cliffs, 1988.

Keckhut, P., Hauchecorne, A., and Chanin, M.-L.: A critical review of the database acquired for the long-term surveillance of the middle atmosphere by the French Rayleigh lidars, J. Atmos. Ocean. Technol., 10, 850-867, 1993.

Keckhut, P., Hauchecorne, A., Bekki, S., Colette, A., David, C., and Jumelet, J.: Indications of thin cirrus clouds in the stratosphere at mid-latitudes, Atmos. Chem. Phys., 5, 3407-3414, doi:10.5194/acp-5-3407-2005, 2005.

Keckhut, P., Borchi, F., Bekki, S., Hauchecorne, A., and Silaouina, M.: Cirrus classification at midlatitude from systematic lidar observations, J. Appl. Meteor. Climat., 45, 249-258, 2006.

Lamquin, N., Stubenrauch, C. J., Gierens, K., Burkhardt, U., and Smit, H.: A global climatology of upper-tropospheric ice supersaturation occurrence inferred from the Atmospheric Infrared Sounder calibrated by MOZAIC, Atmos. Chem. Phys., 12, 381405, doi:10.5194/acp-12-381-2012, 2012.

Lanzante J. R.: Resistant, robust and non-parametric techniques for the analysis of climate data: Theory and examples, including applications to historical radiosonde station data, Int. J. Climatol., 16, 1197-1226, 1996.

Liou, K. N.: Influence of cirrus clouds on weather and climate processes: A global perspective, Mon. Weather Rev., 114, 11671199, 1986.

Min, M., Wang, P. C., Campbell, J. R., Zong, X. M., and Xia, J. R.: Cirrus cloud macrophysical and optical properties over North China from CALIOP measurements, Adv. Atmos. Sci., 28, 653664, 2011.

Montoux, N., Keckhut, P., Hauchecorne, A., Jumelet, J., Brogniez, H., and David, C.: Isentropic modeling of a cirrus cloud event observed in the midlatitude upper troposphere and lower stratosphere, J. Geophys. Res., 115, D02202, doi:10.1029/2009JD011981, 2010.

Noel, V. and Chepfer, H.: A global view of horizontally-oriented crystals in ice clouds from CALIPSO, J. Geophys. Res., 115, D00H23, doi:10.1029/2009JD012365, 2010.

Plana-Fattori, A., Brogniez, H., Chervet, P., Haeffelin, M., LadoBordowsky, O., Morille, Y., Parol, F., Pelon, J., Roblin, A., Sèze, G., and Stubenrauch, C.: Comparison of high clouds characteristics as estimated by selected spaceborne observations and ground-based lidar datasets, J. Appl. Meteor. Clim., 48, 1142 1160, 2009.

Rossow, W. B. and Schiffer, R. A.: Advances in understanding clouds from ISCCP, B. Amer. Soc., 80, 2261-2287, 1999.

Sassen, K. and Campbell, J. R.: A midlatitude cirrus cloud climatology from the facility for atmospheric remote sensing. Part I: Macrophysical and synoptic properties, J. Atmos. Sci., 58, 481496, 2001. 
Sassen, K. and Comstock, J. M.: A midlatitude cirrus cloud climatology from the facility for atmospheric remote sensing. Part III: Radiative properties, J. Atmos. Sci., 58, 2113-2127, 2001.

Sherlock, V., Garnier, A., Hauchecorne, A., and Keckhut, P.: Implementation and validation of a Raman lidar measurement of middle and upper tropospheric water vapour, Appl. Opt., 38, 58385850, 1999.

Stubenrauch, C. J., Chédin, A., Rädel, G., Scott, N. A., and Serrar, S.: Cloud properties and their seasonal and diurnal variability from TOVS Path-B, J. Climate, 19, 5531-5553, 2006.

Stubenrauch, C. J., Cros, S., Lamquin, N., Armante, R., Chédin, A., Crevoisier, C., and Scott, N. A.: Cloud properties from Atmospheric Infrared Sounder and evaluation with Cloud-Aerosol Lidar and Infrared Othfinder Satellite Observations, J. Geophys. Res., 113, D00A10, doi:10.1029/2008JD009928, 2008.

Thorsen, T. J., Qiang, F., and Comstock, J. M.: Comparison of the CALIPSO satellite and ground-based observations of cirrus clouds at the ARM TWP sites, J. Geophys. Res., 116, D21203, doi:10.1029/2011JD015970, 2011.

Twomey, S.: Aerosols, clouds and radiation, Atmos. Environ., 25, 2435-2442, 1991.

Vaughan, M. A., Kuehn, R., Young, S., McGill, M., Liu, Z., and $\mathrm{Hu}, \mathrm{Y}$ : Validating cirrus cloud optical properties retrieved by CALIPSO, ILRC 2008, Boulder, CO, USA, 2008.
Vaughan, M. A., Powell, K. A., Winker, D. M., Hostetler, C. A., Kuehn, R. E., Hunt, W. H., Getzewich, B. J., Young, S. A., Liu, Z., and McGill, M. J.: Fully automated detection of cloud and aerosol layers in the CALIPSO Lidar measurements, J. Atmos. Ocean. Technol., 26, 2034-2050, 2009.

Ward, J. H.: Hierarchical grouping to optimize an objective function, J. Am. Stat. Assoc., 58, 236-244, 1963.

Winker, D. M., Hunt, W. H., and McGill, M. J.: Initial performance assessment of CALIOP, Geophys. Res. Lett., 34, L19803, doi:10.1029/2007GL030135, 2007.

Winker, D. M., Vaughan, M. A., Omar, A., Hu, Y., Powell, K. A., Liu, Z., Hunt, W. H., and Young, S. A.: Overview of the CALIPSO mission and CALIOP data processing algorithms, J. Atmos. Ocean. Technol., 26, 2310-2323, 2009.

Wylie, D. P. and Menzell, W. P.: Eight years of high cloud statistics using HIRS, J. Climate, 12, 170-184, 1999.

Yorks, J. E., Hlavka, D. L., Hart, W. D., and McGill, M. J.: Statistics of cloud optical properties from airborne lidar measurements, J. Atmos. Ocean. Technol., 28, 869-883, 2011.

Zerefos, C. S., Eleftheratos, K., Balis, D. S., Zanis, P., Tselioudis, G., and Meleti, C.: Evidence of impact of aviation on cirrus cloud formation, Atmos. Chem. Phys., 3, 1633-1644, doi:10.5194/acp3-1633-2003, 2003. 